Review Essay

\title{
Performing health in place: The holy well as a therapeutic assemblage
}

\author{
Ronan Foley* \\ Department of Geography, National University of Ireland, Maynooth, Co. Kildare, Ireland
}

\section{A R T I C L E I N F O}

\section{Article history:}

Received 5 August 2010

Received in revised form

23 November 2010

Accepted 27 November 2010

\section{Keywords:}

Therapeutic landscapes

Performance

Indigenous health

Holy well

Ireland

NRT

\begin{abstract}
A B S T R A C T
This paper examines the holy well as a representative therapeutic landscape with a particular focus on linking a traditional setting with contemporary theory associated with the 'performative turn'. This is developed within the paper to suggest a new theoretical model of the 'therapeutic assemblage' containing material, metaphoric and inhabited dimensions. Drawing empirical evidence from Irish holy wells, complex holistic performances of health are identified within such settings. Deeper associations with more-than-representational theory suggest new directions in the study of therapeutic landscapes to uncover the importance of cultural practice and lay narratives of healing in the creation of healthy place.
\end{abstract} (c) 2010 Elsevier Ltd. All rights reserved.

\section{Introduction: the holy well as a therapeutic landscape}

'Who says the well is holy? Why? If there is a fence, or a gate, or a covering over the well, who built them? Who has left these tokens, and how long ago? Are we trespassing? What is expected of us? Is this religion, or magic, or folk medicine? Is it a Catholic devotion, or something older? Is it unique to Ireland? If this is an ancient site of worship, why are there ashtrays and broken china, canteen chairs and modern statues? Does the water have special properties? Is anyone in charge? If there are stories about the well, where are they written? Who is this saint whose name is attached to it? Should we have come on a special day? (Bourke, 2001: 7)

Holy wells exist as healing and spiritual sites across the globe and reflect wider cultural and phenomenological place connections to other forms of holy and healing waters like lakes and rivers (Bord and Bord, 1985; Rattue, 1995; Foley, 2010). In addition there are commonly found culture-nature expressions of the role of springs and sources as marking the boundaries between the human and spiritual underworlds (Shackley, 2001). Well settings are often framed by streams, stones and trees, which act as markers of a connection between the grounded earth and the sky, spiritual and imagined home of the gods (Jones and Cloke, 2002; Shaw and Francis, 2008).

As 'hydro-therapeutic' settings containing a combination of natural and built elements, there are approximately 3000 holy wells currently dotted across the island of Ireland. While their pagan origins are debated (Rickard and O'Callaghan, 2001; Gerten, 2008), they contained elements of nature worship and hydrolatry, which

\footnotetext{
* Tel.:+3531708 6024; fax: +35317083573.

E-mail address: ronan.foley@nuim.ie
}

were subtly absorbed into early Christian place hagiography (Carroll, 1999; Logan, 1980; Healy, 2001). After a period of concentrated use between the mid 17th and mid 19th centuries, they fell out of favour after 1850 as a centralising church developed more formal sites to explicitly increase its own cultural power (Harbison, 1991). Yet they retain a presence and power in contemporary society and many of the associated performances and narratives of health have sustained and even recovered in place.

Materially, they range from literal holes in the ground to substantial landscaped sites with a mix of natural and culturally introduced elements. In general, the sites contain the wells themselves, streams, stone crosses and covers, paths, trees and bushes, altars and statues, all of which have physical form but wider symbolic meanings as well (Brenneman and Brenneman, 1995; Foley, 2010). All express Strang's (2004) notion of being 'typical and unique' across horizontal space and vertical time. Holy wells were also subjected to deeper cultural and political scrutiny that shaped their dual roles as physical and spiritual curative sites. As geographical settings in which 'faith cures' were enacted, these in turn were interpreted and managed by a range of controlling agents (Ó'Cadhla, 2002). As sites of liminal behaviour and independent native identity, the gaze of controlling agents such as the Catholic Church and the ruling British colonial government was evident in different historic periods (Carroll, 1999).

Such settings can also be described as therapeutic landscapes, places that have achieved lasting reputations for providing physical, mental and spiritual healing (Kearns and Gesler, 1998). Initially focused on spas and pilgrimage sites, therapeutic landscape research has developed to include settings like gardens and wilderness, as well as formal health sites designed to induce wellness (Gesler, 1992, 1993, 1996, 1998; Williams, 1999b; Williams, 2007). In seeing natural 
settings like wilderness as therapeutic, there are strong connections back to early humanist and phenomenological research on personlandscape interactions (Tuan, 1974; Wylie, 2007). These earlier studies also identified that phenomenological and imaginative responses to wilderness were often expressed as manifestations of the sacred, with the nature-religion link often expressed in therapeutic terms (Eliade, 1961; Graber, 1976).

Broad therapeutic landscape classifications have been developed by Gesler (1993) and Williams (1999a) with the latter hinting at a more experiential dimension. A specific definition by Gesler noted that therapeutic landscapes consisted of two key psycho-cultural components:

'Inner/meaning (including the natural setting, the built environment, sense of place, symbolic landscapes, and everyday activities) and Outer/societal context (including beliefs and philosophies, social relations and/or inequalities, and territoriality)'. (Gesler, 1993: 173).

How the 'inner/meanings' of such therapeutic spaces are negotiated against their 'outer/contexts' is at the heart of understanding their healing potential and cultural meanings in health terms. How individuals experience healing in place can be studied in a number of different settings, many of which are associated with water (Gesler, 1998). Some watering places, such as modern spas, have identities of mind-body-spirit health, linked to a range of new age treatments and contemplative spiritualities (Shaw and Francis, 2008; Foley, 2010). Yet it is an older form, the holy well, which provides a valuable setting to conceptualise more fully a broad range of health performances, enacted within a therapeutic space.

\section{Performative turn and therapeutic space}

Current theoretical discussions in cultural and health geographies suggest that the holy well has potential as a valuable representative place within which to study performances of health (Jackson, 1989; Kearns and Moon, 2002). Recent critical discussions on the nature of therapeutic spaces recast them as sites of therapeutic potential (Conradson, 2005). One cannot assume a fixed therapeutic meaning or outcome associated with an individual setting and at times, outcomes may even be anti-therapeutic (Collins and Kearns, 2007; Conradson, 2007; Lea, 2008; Dunkley, 2009). In this contested view, Conradson (2005) suggests that the 'therapeutic landscape experience' can be viewed as a relational outcome;

'In these nuanced interpretations, particular landscapes are found to be not intrinsically healthy or unhealthy; rather they may be used, experienced and perceived differently by different people ... In general terms, a therapeutic landscape experience might then be understood - from a human point of view - as a positive physiological and psychological outcome deriving from a person's imbrications within a particular socio-natural material setting' (Conradson, 2005: 339).

This interest in imbrication suggests a material and experiential presence and practice in such settings wherein individuals can potentially derive physical, mental and spiritual benefits. Yet these imbrications occur in therapeutic settings that are externally affected by wider material cultures and economies that shape their production and meaning.

From recent theoretical debates within cultural geography, discussions around the 'performative turn', framed by phenomenology but developed through post-phenomenological approaches like non-representational theory (NRT) can also be aligned with critical therapeutic landscapes research (Rose and Wylie, 2006; Lorimer, 2006; Anderson, 2010). Early phenomenological research was important in suggesting landscapes as experientially 'lived in', where a 'sense of place' and crucially, well-being, were central (Tuan, 1974; Wylie, 2007). Performative connections were also drawn from the work of Ingold (2000) and Merleau-Ponty (1962) via inhabitations that were: "embodied, entwined with a lived temporality which is performed and enacted, in an indissoluble connection between person and landscape" (Wylie, 2007: 161). Merleau-Ponty's description of the senses as essentially spatial, 'a spatiality that enacts meanings in the lived-body's engagements and negotiations with its milieu', further emphasises the embodied nature of such inhabitations (Backhaus, 2009).

Within post-phenomenological theory, the senses and their precognitive dimensions are more explicitly introduced (Rose and Wylie, 2006; Lea, 2009). In thinking through where embodiment and the senses fit within the wider 'performative turn', the word affect also features prominently (McCormack, 2004; Paterson, 2005). Sometimes erroneously used as a synonym for emotion, I prefer to see it geographically as a connective concept between embodied instincts and their expression in a set of 'places of the senses', where emotional, pre-cognitive and subconscious dimensions of healing are triggered and experienced (Anderson and Smith, 2001; Eyles and Williams, 2008; Dewsbury, 2009; Lea, 2009). Affective experiences are also embodied, such that reflexive relationships emerge between bodies, minds, spirits, health and place.

NRT concerns whereby representational approaches to landscape were challenged by more concrete/material engagements in place through bodies and the situated self were also important in reassessing the therapeutic landscape (Crouch, 2000; Lorimer, 2008; Thrift, 2008). Importantly, Lorimer suggested the term 'more-than-representational', as a better expression for NRT that accepted the continuing importance of metaphor, text and symbol, but set this alongside equally important material and inhabited expressions of place (Lorimer, 2005). All of these theoretical shifts towards spaces of performance and inhabitation are directly applicable to the holy well, where relational ownerships and embodied enactments of health are developed and negotiated (Rose and Wylie, 2006; Thrift, 2008).

The potential to more fully apply performative theory to therapeutic landscape settings has been identified as both challenge and potential by Wylie (2007), who suggests the need for a new engagement in these themes by researchers in the field. This challenge will be met, noting that such phenomenological and inhabited concerns have longer histories than are sometimes acknowledged (Dorn and Laws, 1994; Kearns, 2005; Williams, 1999b; Dyck et al., 2005). Applying these new performative ideas to old or 'special' therapeutic settings might appear retrogressive, given current interests in the contemporary and everyday (Milligan and Bingley, 2007; De Certeau, 1984). But I believe the holy well, a 'somewhere-betweenspecial-and-everyday' place, and one that sustains its historical meanings in contemporary practice, may prove a valuable grounded study setting. As a setting that combines affect (as person-place disposition and spirit-faith presence) and performance (as emotional expression and embodied practice), it sits comfortably with Conradson's (2005) reworking of therapeutic experiences that incorporate physiological and psychological responses to place.

In more fully embedding connections between therapeutic landscape and performance, I propose a template (Table 1) for a 'therapeutic assemblage' that is shaped by specifically material, metaphorical and inhabited dimensions (Deleuze and Guattari, 1987; Lorimer, 2009). While such a concept owes a debt to actornetwork theory and in particular the work of Deleuze and Guattari in utilising the notion of the assemblage as a set of productive connections, these are extended to an empirical setting with a specific therapeutic identity. The material would incorporate tangible bricks and water places, flesh and blood people and documented and experienced cures. A sense of 'being in' also emphasises the ongoing significance of an experiential and embodied imbrication within a 
Table 1

Theoretical model of the therapeutic assemblage.

\begin{tabular}{llll}
\hline Structures & Material & Metaphorical & Inhabited \\
\hline Theoretical terms & Embodiment & Affect & Performance \\
Health and well-being & Body & Mind & Spirit \\
\hline
\end{tabular}

therapeutic environment (Ingold, 2000; Conradson, 2005). Metaphors, so central to the making of therapeutic landscapes, are expressed in cultural narratives, reputations and crucially in a site of spiritual healing, beliefs (Williams, 1999a). Here the ongoing significance across time of a representative take on healthy place remains important (Gesler, 2003). Finally, and a dimension this research aims to foreground more fully, the inhabitation of place strongly reflects theoretical ideas drawn from the performative turn with its attention to more-than-representational lived, experiential and performative dimensions of health in place. In considering definitions of health within the assemblage, those used draw from an interest in mindbody-spirit health. This is in turn used alongside a set of theoretical dimensions, namely embodiment, affect and performance, to construct a template of three by three interconnected themes.

In designing such an assemblage, the connective ideas can be read as a definition of therapeutic landscape that emphasises connections, not always necessarily productive, between inner meaning and outer/societal context and the more experiential and relational dimensions required of contemporary work in this area (Conradson, 2005, 2007). More usefully, energies, a term hinted at but under-used in performative texts, is a key ingredient in this spatial stew, especially when associated with health and healing (McCormack, 2004; Lea, 2006; Lorimer, 2006). Material settings and bodies hold within them a range of potential energies, those energies have symbolic healing associations and it is through energetic performances of health in place that productive aspects of the assemblage, wherein affect becomes performance, are expressed. In illustrating these energies of health within the holy well, the deeper potential of the therapeutic assemblage will be proposed and explored.

\section{Data and method}

This work draws the bulk of its empirical material from detailed study of ten representative wells spread across Ireland (Foley, 2010). The choice of wells was based on a number of criteria, namely the presence of well-documented and archival accounts of practices, the existence of contemporary 'patterns' for observer participation and a geographical spread across the whole island (Fig. 1). In examining a range of holy wells, inhabitation has been incorporated into the methods employed in the research, through visits to wells, collections of oral narratives, conversations and participant observations. These methods also reflect Nash's (2000) suggestion that putting theories of performativity to work in discussing specific practices makes for better theory. While a significant proportion of the material was drawn from the author's own observer participation, this was supplemented by local informants such as members of local parish groups and historical/heritage organisations and by informal encounters with active participants at the wells. A theoretical justification for such an approach would also be rooted in the need to use a range of ethnographic, visual and performative methods to try and get closer to the objects and the practices of people in real time (Lorimer, 2009).

The specific wells included three dedicated to St. Brigid (Faughart, Tully and Liscannor) and wells associated with St. Declan (Ardmore) and St. Kieran (Castlekeeran). Another four wells, Struell, Lady's Island, Tobernalt and Doon, had less explicit affiliations with a local saint while the last well, Father Moore's, was

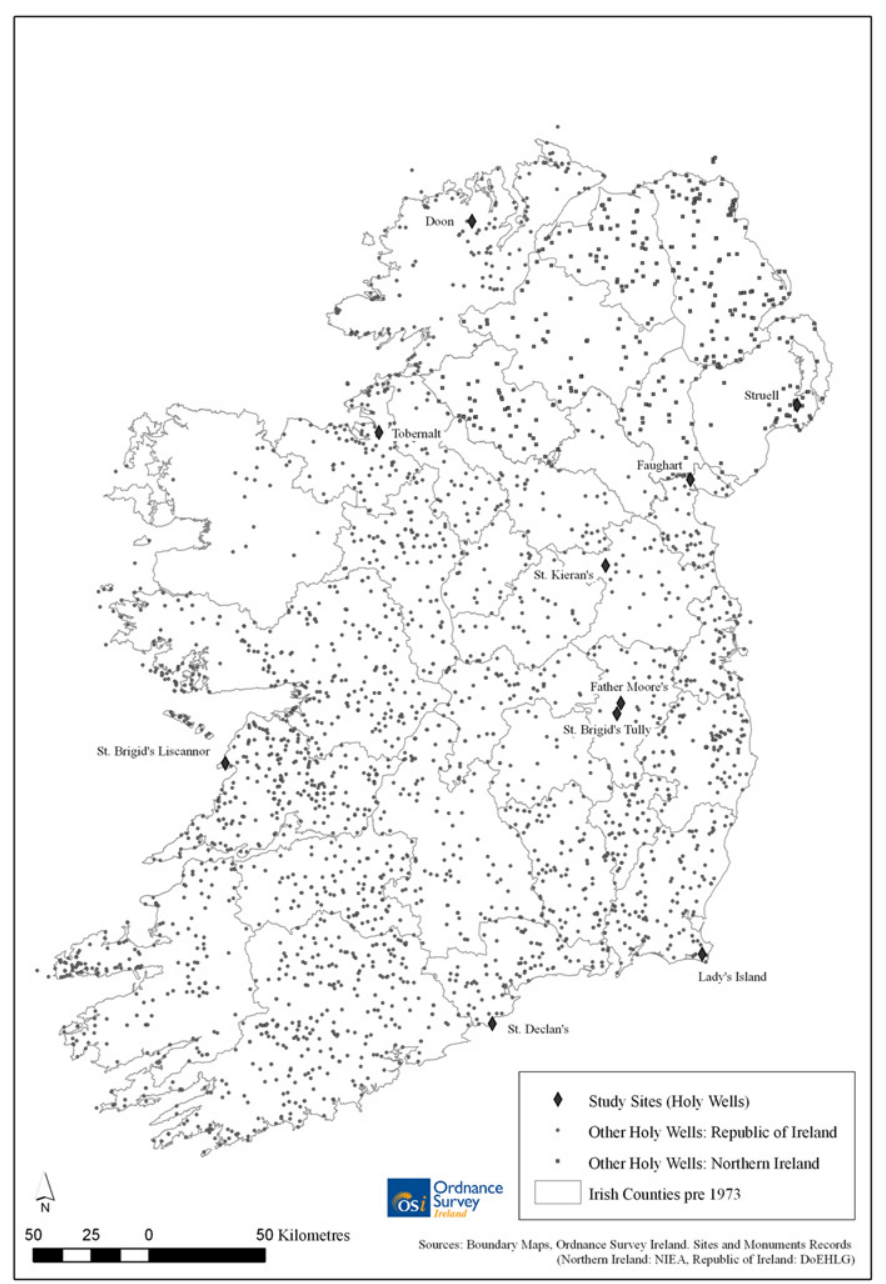

Fig. 1. Location map of representative and other holy wells.

named after a nineteenth century healing priest. All wells were visited two to four times, including where possible on official ritual 'pattern' days. The historical material on the wells was drawn from archival and historical sources, from which material on performances and medicine/health were extracted. In addition, the deeper secondary material on the cultural meaning of the holy well was identified from wider anthropological, folklore and historical writing (MacNeill, 1982; Taylor, 1995; Ó'Cadhla, 2002). While much of the material had an implicit relationship with place, it had not been used previously to draw out a deeper critical take on health geographies or as a 'more-than' representational engagement with therapeutic landscape.

\section{Material place, embodiment and bodily health}

In considering holy wells as material settings, where built/natural environments and human (and occasional non-human) forms interact, it is useful to illustrate these assemblage elements. There are aspects of embryonic therapeutic design implicit in constructions in and around holy wells (Gesler and Kearns, 2002). While for very local wells, this often consists solely of a literal hole in the ground or a small stone covering, in the larger representative wells, there are a range of designed elements. Five of the wells are covered, such as at Ardmore, visibly housed within a 15th century stone enclosure with carved stone crosses and separate entrances providing access to the supervised well waters (Fig. 2). Both wells at Struell are enclosed within small corbelled buildings, one square (the Eye Well, see Fig. 3), the other circular 


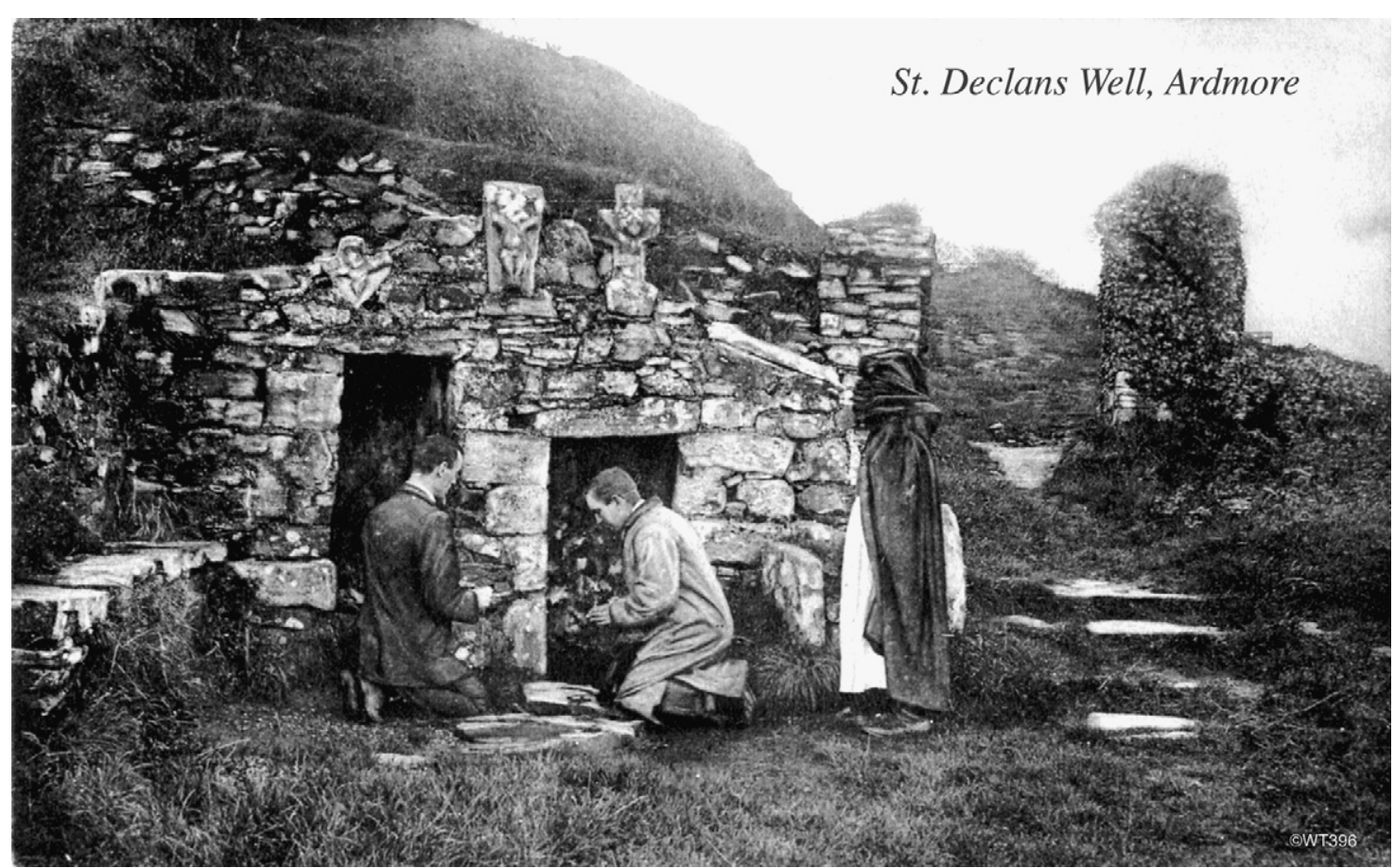

Fig. 2. St. Declan's Well, Ardmore.

Source: Irish Heritage Giftware, info@ihpc.ie

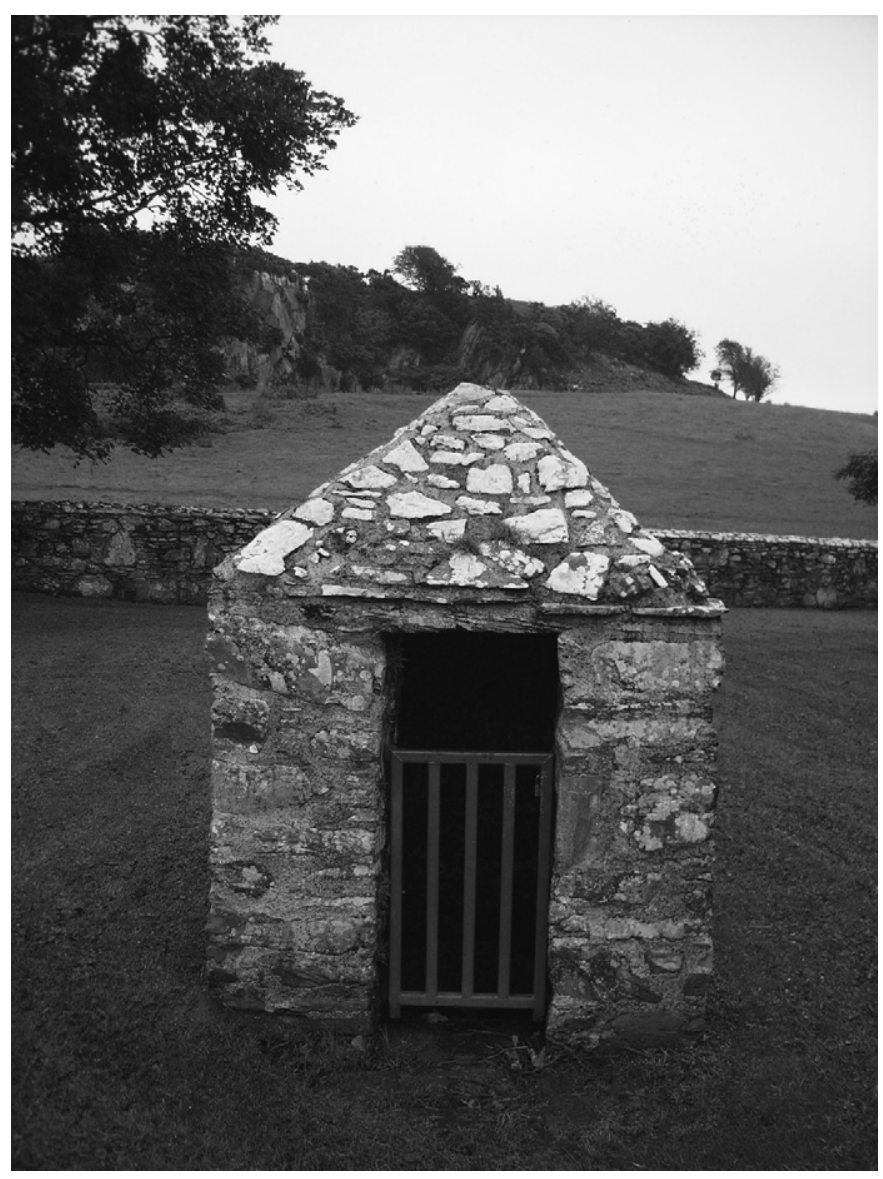

Fig. 3. Struell Wells: Eye Well.

(the Drinking Well); both rebuilt from previously ruinous conditions. Here the names of the built objects speak directly to specific embodied cures. Other wells, while open to the sky, are surrounded by substantial stone walls, some rough and old as at Tobernalt and Liscannor, others of smoother recent construction as at Tully and Fr. Moore's. At Castlekeeran, the main well setting is partially sheltered by an overhanging tree with a rough limestone rock surround, where visitors can bend to drink the curative waters (Fig. 4). At Liscannor, although the well itself is open, it is approached through a tunnel-like cave, about ten metres long within which large amounts of left offerings are piled on ledges and walls (Fig. 5). In these images one can see the affective built settings, containing formal catholic iconography and objects alongside more natural elements of stone, water and wood.

In considering wider theoretical concerns with embodied health it is also useful to consider the physical body within this particular space. From their foundations, well sites have been used for a mixture of spiritual and curative purposes (Logan, 1980). The holy well is an assemblage within which healthy and unhealthy bodies co-exist. Unhealthy bodies come especially in search of healing and the range of attributed cures for a vast range of illnesses and conditions is an abiding and formative narrative at the well. As a strong discursive and pragmatic driver of embodied utilisations, documented 'cure' treatments ranged from those for sore eyes (Struell and Faughart) and toothache (St. Kierans's) to more medicalised examples such as lumbago (Ardmore), arthritis/rheumatism (Doon, Liscannor, St. Kierans's) and even cholera at Tobernalt during the 1830 s outbreak. While most wells might not withstand biomedical scrutiny, they are sustained by deeper narratives of a curative power and belief is at the heart of these expressions of an embodied 'faith cure'. At many wells, rag trees and bushes mark a visible example of this process at wells such as Tobernalt (Fig. 6) and Lady's Island. Here rags are rubbed on affected body parts and left on the bush or tree. In the act of tying that rag or other object to the tree, that object should be something that touched the body and thereby metaphorically transferred a body part, itself discursively representing a bodily illness, to the natural curative place. Here the wider power of the water acted on the rag to reduce or cure the 'left' symptoms/illness as the rag itself deteriorated over time. At Tobernalt, many of the rags are left for years, yet are also added to on a daily basis. Yet the body is also a site of enactment where pilgrims kneel in the holes, allegedly left 
by the saint, as at Faughart (Fig. 7) in a literal embodied act of spiritual cure. As an example of the mobility of embodied practice, it is also common to see pilgrims kneel on the top of this stone as

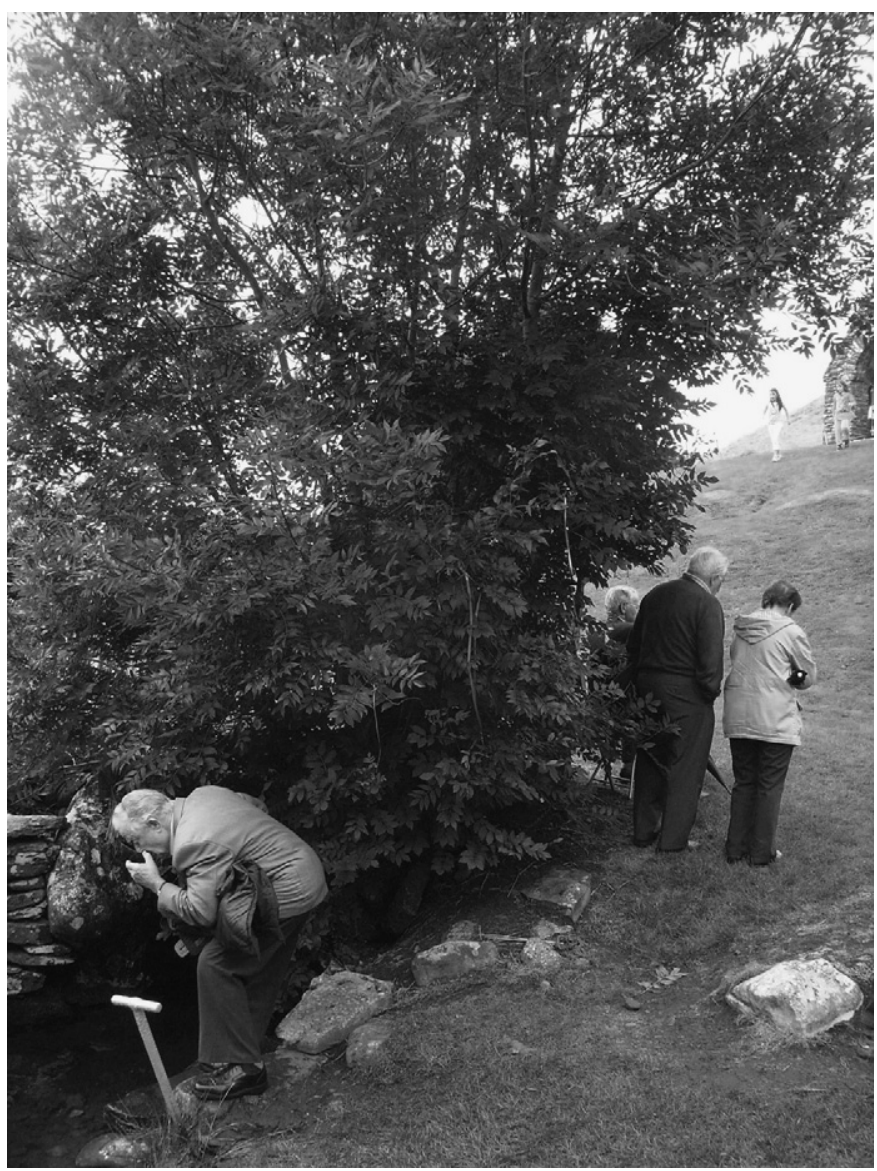

Fig. 4. St. Kieran's Well, Castlekeeran: Main Well. well as in the grooves. In other wells, there are specific instructions to specific body-part cures such as a sign at St. Kieran's identifying a natural curve in the limestone as being good for 'ailments of the back' (National Folklore Collection, 1934; O'Connell, 1957). In addition, the stream in front of the well was used for curing lame horses well into the 20th century.

In seeing embodiment as both a physical and an imaginative experience, the long history of bodily healing is sustained and reproduced. Many of these curative narratives have a deep provenance and provide a link to a wider notion of health histories in place, even when applied to 'small places' (Andrews and Kearns, 2005; Cummins et al., 2007). In addition, one can glimpse in the material places of the therapeutic assemblage examples of representational objects, via more formal church elements such as altars, crosses and even small oratories on what were previously relatively natural and organic sites as at Faughart and St. Kieran's. At Father Moore's well an informant provided a narrative of a chronically damaged back that the experts at the Blackrock Clinic couldn't cure'. He noted however that upon wearing the curative object of Father Moore's hat, brought out once a year to the well, his back healed sufficiently to allow him to return to the well with his grand-children, relatively fully mobile, within a week. Such objects suggest that as well as the imagined physical cures that are reputationally associated with such spaces, deeper and often contingent healing also emerges.

\section{Metaphor, affect and mind health}

While the material sites contained the curative waters, it was the therapeutic narratives related to a broad faith cure that cemented deeper health metaphors within the assemblage. There were suggestions that the mineral make up of the well water (they were often mixed up with spas), provided an evidence base for physiological benefits (Bord and Bord, 1985). But it was in oral traditions of dinnseanchas, the Irish term for place lore, that their healing reputations were maintained. While many wells had strong parallel identities as places of pilgrimage, Taylor (1995) noted that wells held stories and existed symbolically as non-silent

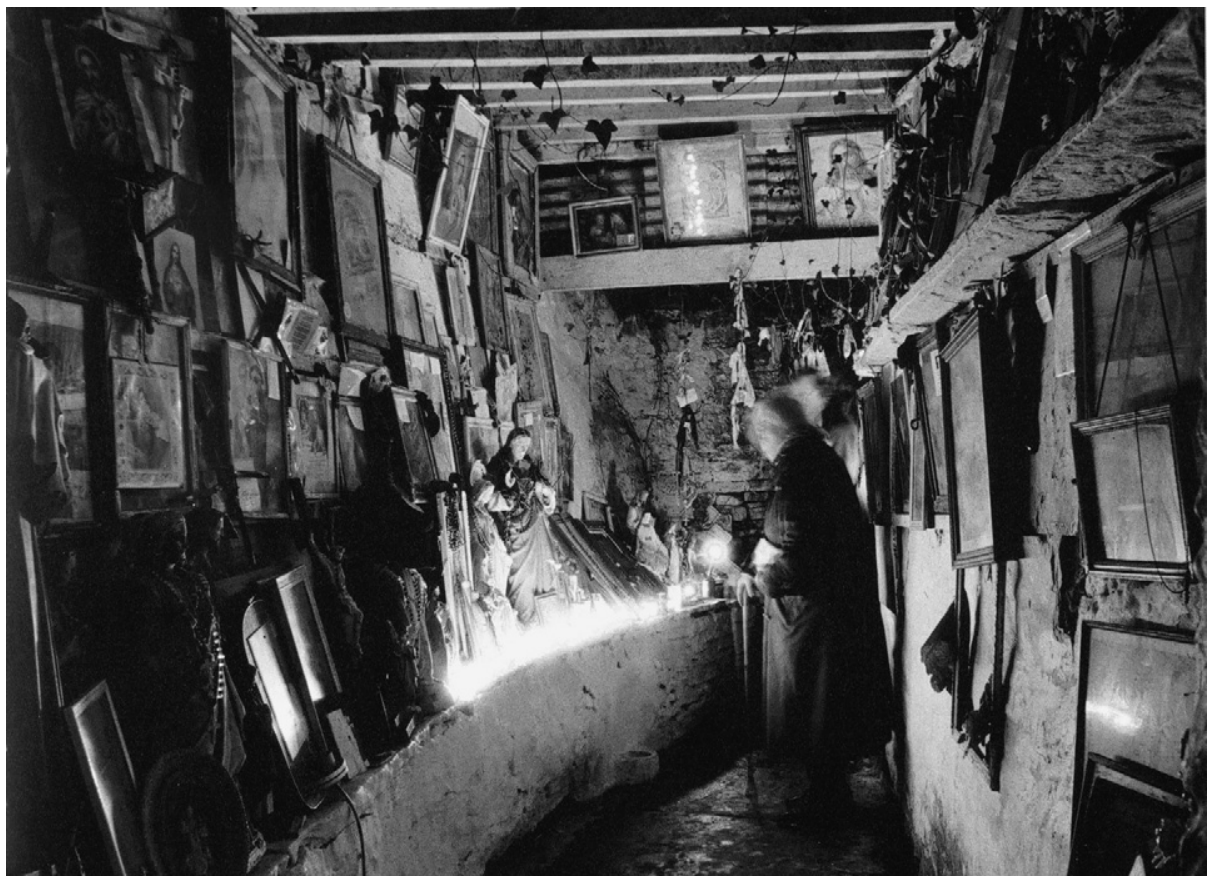

Fig. 5. St Brigid's Well, Liscannor.

Source: Anne Rickard and Liam O'Callaghan. 


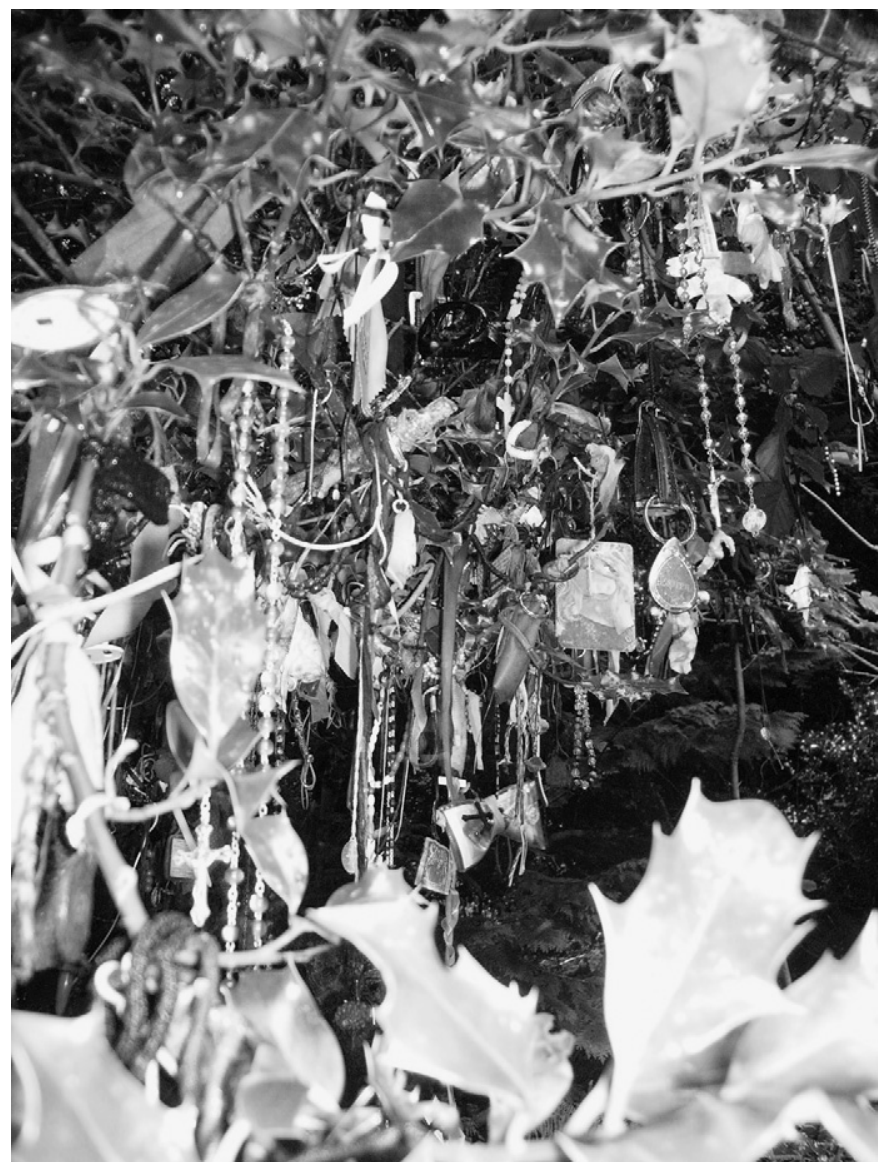

Fig. 6. Rag bushes at Tobernalt Holy Well.

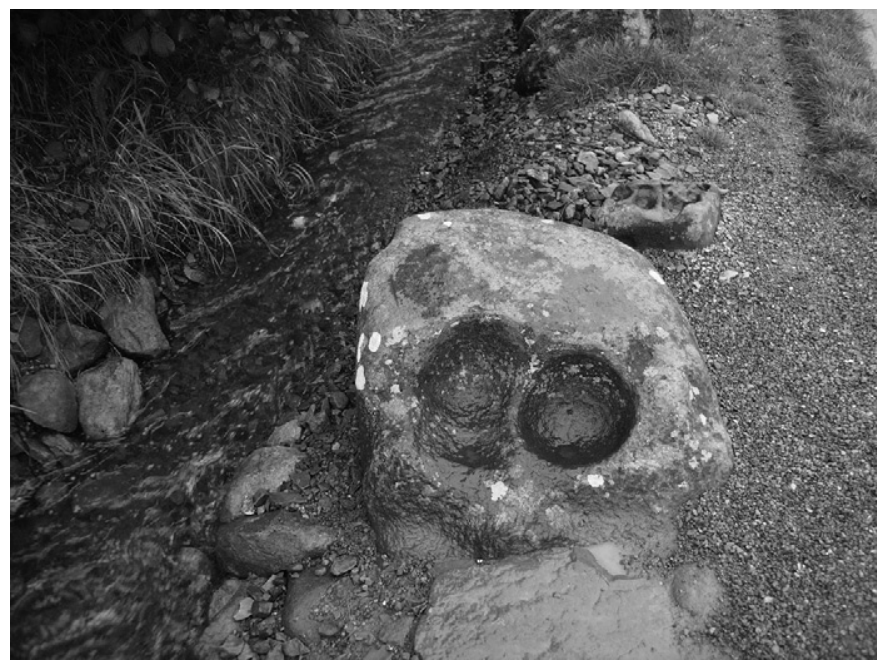

Fig. 7. St. Brigid's Shrine, Faughart: Pilgrimage Stones

landscapes. In the 1930s in Ireland such stories were recorded for a national archival collection with a particular attention to wells, where a typical narrative for St. Kieran's noted:

further away still is a smaller well covered over with rock with an opening on either side. Water from one side is supposed to cure headache, water for the other side cures toothache' (National Folklore Collection, 1934).
In these deeper symbolic narratives, the waters were also holy and holistic, drawing their power from the sacred and spiritual and applicable to a wide range of aliments and conditions (Varner, 2002). Clearly there are and were contestations of this assumed curative power and rationalist medical responses saw and see the wells as superstitious sites of pseudo-cure inhabited by the credulous and ignorant. A visitor to Ardmore in 1867 noted 'you are expected to drink a glass of water, which is nothing but ordinary spring water' (Ó'Cadhla, 2002). This contestation of the 'medical' value of the site failed to take into account deeper meanings, many of which were associated with the energies of both the place itself and its affective reputation as a site of renewed energies. A traveller visitor to Lady's Island in 2009 noted in a cautionary sense, that 'you need to be careful with it, there's a great cure in that well', while the healing energies at wells were considered strongest on the night of patterns as noted by a local informant at St. Kieran's. Given the strong religious and spiritual metaphors associated with the well sites, their value in health terms was associated with more holistic understandings of well-being (Bergholdt, 2008; Knott and Franks, 2007).

Cures were also contingent practices, based on a suitable respect for the water and the spiritual identities of the place, wherein anthropological notions of gift-exchange were visible, with the gift of health being repaid by metaphorical offerings and symbols. A failure to meet these requirements was often considered to have an anti-therapeutic effect, reflecting recent concerns with contested health outcomes (Conradson, 2005). These narratives were often punitive moral tales, for example water from wells was not supposed to be used for cooking and those who took it generally came to an unfortunate end, with sudden death within a fixed period of either three days, three weeks or three months being a reputed punishment at Liscannor (Brenneman and Brenneman, 1995). Yet the persistent survival of such stories serves to strengthen an energetic and respectful phenomenological connection between use value and symbolic power (Harbison, 1991).

In considering the function of wells as providing a form of 'mind healing', the place of affect becomes significant. In settings where water, stone, wood and leaf are all present the peaceful connections with nature are sensually enhanced (Figs. 2-7). These affective aspects have clear links to the foundational ideas of the therapeutic landscape as retreat/restful asylum (Gesler, 1992). This experiential engagement in and with place can be enacted in quiet moments by individuals or by communal performances such as patterns and pilgrimages, which also sustain the healing narrative (Turner, 1973). Visitors interviewed at Tobernalt and Tully all spoke of the sites as places 'to reflect and find peace'. Here, the sights, sounds, smells, touches and tastes are augmented by a core 'sixth' sense, feeling. In their capacities as spaces of 'stillness', wells also enhance those more contemplative and spiritual dimensions of a personal mental health (Conradson, 2007). Indeed Tobernalt (Fig. 8) has one derivation of its name as a 'well of the insane', providing a 'loc fás' or hermitage, for patients and lepers living on a nearby island in Lough Gill in the 17th century. Specifically noted in an archival folklore survey from the 1930 s, the water was to be used, "in all ailments but especially for mental ailments” (Boylan, 2002).

More recently, holy wells have developed new meanings around grief, hope and memorial, exemplified by left offerings marking premature death, serious illness and loss. The cave at Liscannor (Fig. 5) is an especially intense example of this, with Mass cards, childhood pictures and shoes, but similar offerings are found at Tobernalt (Fig. 6). Here the capacity of the visitor to seek, and often find, solace and peace marks a further affective dimension to the role of the holy well as a site of mental health. While that peace may be ephemeral and momentary, it is an emotional response that can be profoundly affecting and becomes a lingering ripple, as with many memorial settings, which resonate beyond the space into everyday lives beyond. 
At sites, both past and present, abandoned shoes or crutches were also to be found as markers of an affective response to place (Fig. 9). The abandoned crutch is of course a global metaphor for the

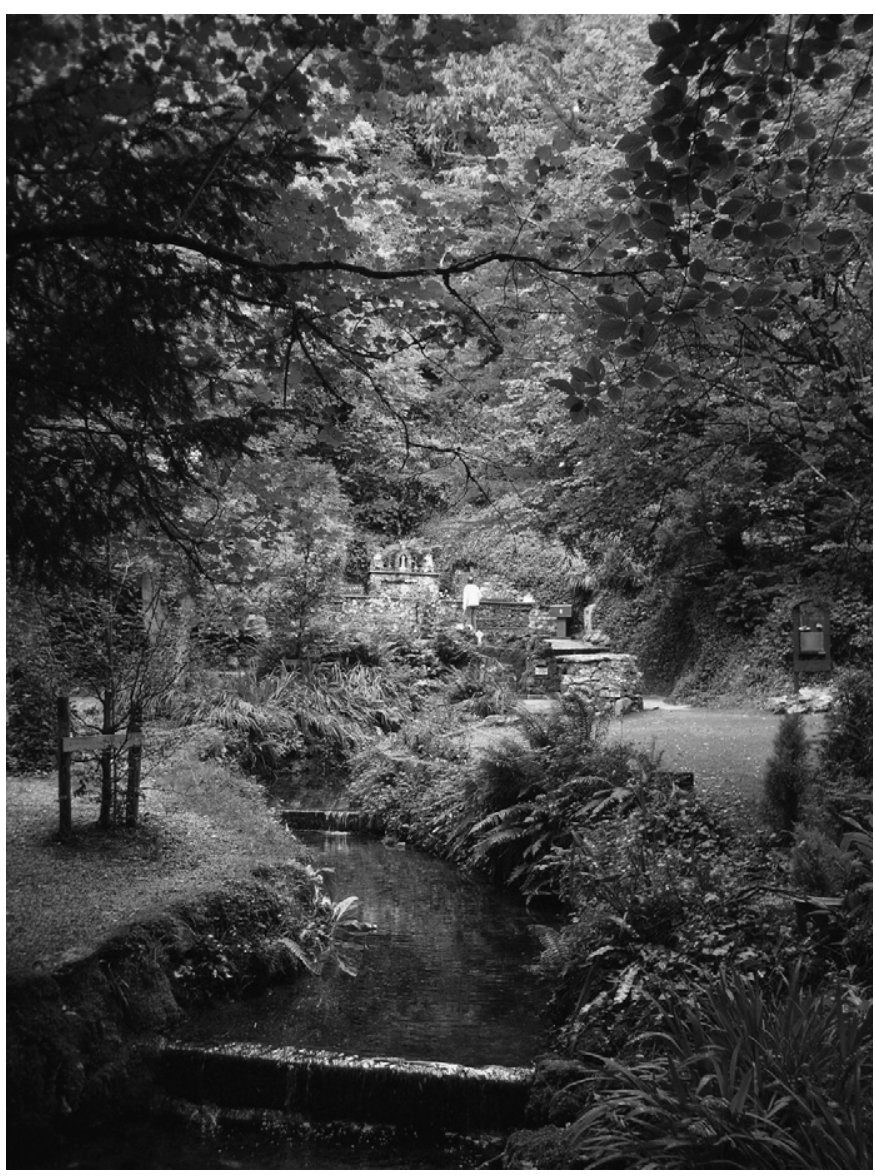

Fig. 8. Tobernalt Holy Well. successful cure, as visible in the past at Banff Springs as it is currently in Lourdes (Gesler, 1996). This image of Doon Well at the end of the 19th century shows that in the absence of a physical bush or tree, pilgrims took to embedding their crutches in the ground beside the well, which in turn assumed a new status as an artificial branch around which subsequent visitors wrapped rags and other offerings. Here a material, yet representational act, further played with the sense of an assemblage that was constantly mobile and mutable, as noted by the actions of the pilgrims in the image.

\section{Inhabitation, performance and spiritual health}

In considering inhabitation at the well, rituals and daily enactments exemplify the notion of a set of health performances but also reflect a shift from affect to action (Turner and Turner, 1978; Gesler, 2003). In the everyday visits to the wells, the carrying out of stations or, in Irish, turas is what Carroll (1999) refers to as rounding rituals, observable in cultures as far apart as India and Sudan. These rituals are carried out by the visitor/penitent in order to access the benefits of the well, both spiritual and physical. They are expressed through sets of specific prayers in specific amounts at specific points within the therapeutic setting. More formally, the pattern day (or week) was based on the patron saint's birthday. While patterns saw a more intense practice of rounding rituals they were also historically the settings for profane, even anti-health behaviours. In many wells, religious observances were carried out up to midnight on the eve of the saint's birthday and then the rest of the night was given over to socializing, dancing and singing (Hall and Hall, 1843). At St. Brigid's Well in Liscannor, particular attractions were singers from the nearby Aran Islands, who would row over en masse to perform through the night.

However, the social aspects also saw lots of drink, which invariably led to a range of liminal and carnivalesque behaviours associated with violence (faction-fighting) and sex (Bakhtin, 1984; Ó'Cadhla, 2002). These were recorded at Ardmore in 1810 with the arch observation that the penitents had: "bloody knees from devotion, and bloody heads from fighting” (Hardy, 1836). At Struell,

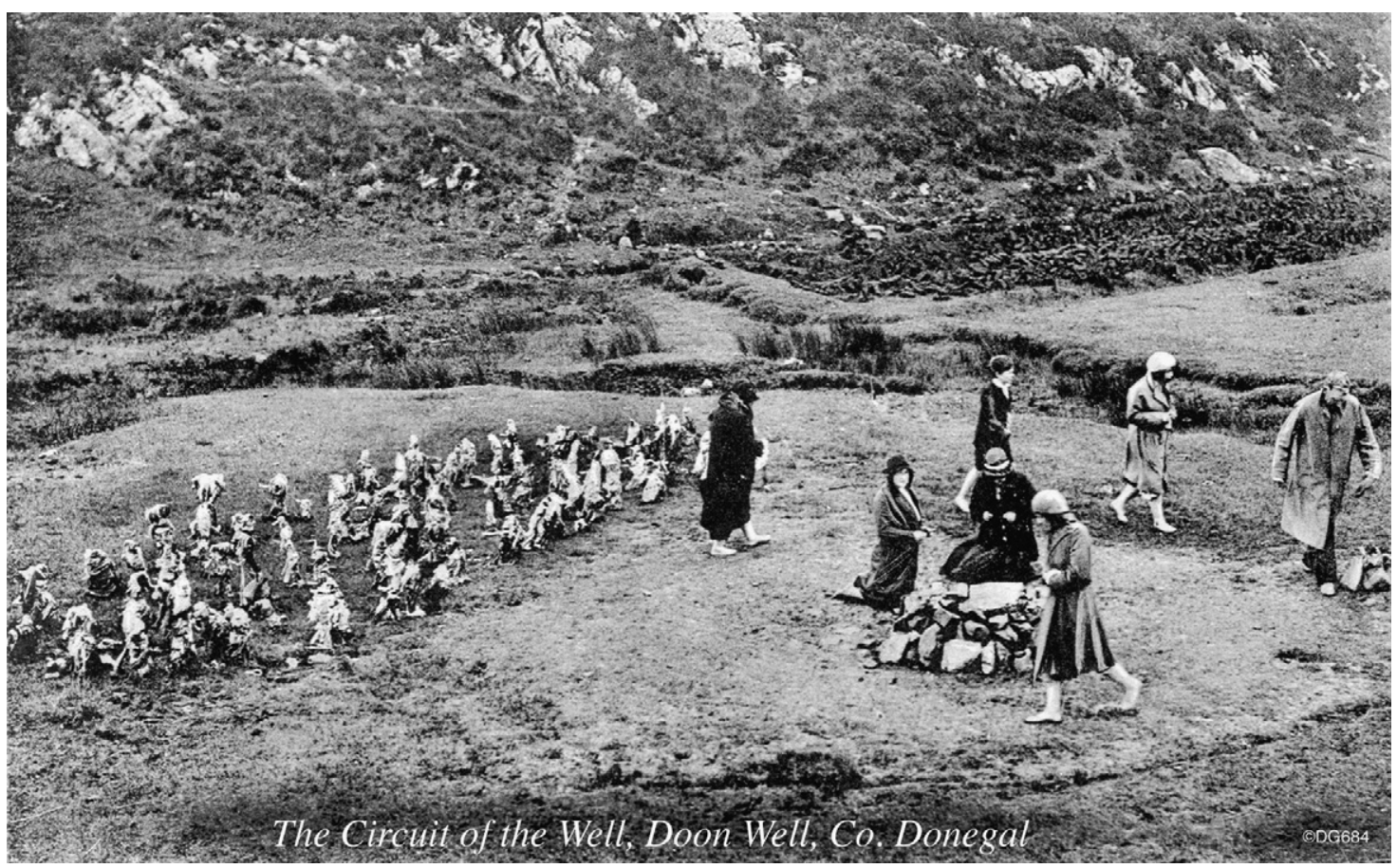

Fig. 9. Crutches and rounding rituals at Doon Well.

Source: Irish Heritage Giftware, info@ihpc.ie 
promiscuous naked bathing by both sexes was followed by 'indulging in various gratifications to which the time and place are favourable ... as long as the happy multitudes remain on the sacred ground, they cannot contract new guilt' (Hardy, 1836: 39). Ultimately this led to concentrated 19th century campaigns by both church and colonial state, the former for reasons of morality, the latter due to concerns with public order, which led to the decline of well worship.

Finally, the openness of the holy well site meant, and still means, that individuals are drawn to such sites of stillness to negotiate their own, spiritual, curative and restorative performances in and with place. Though as often places of sociability as solitude, these performative enactments, especially those related to ritual and symbol, show the strong connections between the bodily spaces, the curative metaphors and the inhabitations of the therapeutic spaces themselves (Broderick, 1998; Conradson, 2005).

Considering these as performances of spiritual health provides an additional way for healing and well-being to be conceptualised as an affective practice. Given that the therapeutic aspects of place feature prominently in the literature, the wells express this in settings containing strong natural elements of water, stone, tree and bush. Holy wells, large and small, are quietly affective places. This is in part tied in to the physical settings, often, though not exclusively in remote places (all ten wells were at some distance from the nearest town), where the natural and built components are a hybrid mix of earth and stone, light and shade, sounds and silences. In these contemplative spaces, one's own embodied experience can be expressed in those affective dimensions of mood and emotion, linked to a range of health elements of anxiety, hope, belief, grief, but also of wonder, amusement, curiosity and joy. While individualised actions are allowed the need to conform to 'ritual inhabitations' is less strict than it once was. Yet the morethan-representational practices carried out by well visitors extend these connections more deeply in a performative sense as active engagements by individuals in their own health via transient but repeatable practices (Lea, 2006, 2008). The image of the decorated interior of St. Brigid's at Liscannor (Fig. 5) shows the intensity of the left offerings but also represents a range of affective and emotional states of hope and despair, characteristic of certain health statuses such as incurable disease or chronic illness (Conlon, 1999; De Vál, 2007).

Lest it be thought that the holy well is a relict of the past, it has a contemporary relevance and performance as well. In looking at the resilience of the well through the lens of a therapeutic assemblage, mobilities of meaning and re-tellings of place-health identities all play a role. The mobility of the cure is tied to the waters of the place, both potable and portable, which can be consumed in situ, or equally importantly taken away for use as a general prophylactic in the everyday home place by those too ill to come. Older performances of health have been augmented by new meanings, still with affective health values, as places of memorial, gratitude and supplication. More recently patterns have been revived at Tully and Faughart and are often jointly celebrated by catholic and neopagan groups though not without some tensions and contestations. In a new-age vision of spirituality, a concern with nature and new understandings of the sacred, often expressed in body-landscapeenergy terms, find natural expression within holy well sites. At the 2010 pattern at St. Brigid's Well, Tully, a group of female Breton visitors noted that they celebrated Brigid as a neo-pagan goddess and provider of deep spiritual healing and as an embodied energy that could 'light their fire'. Yet throughout holy well histories, wider notions of a faith cure have sustained primarily through inhabitation and narrative, often as much through small everyday visits as the more concentrated pattern day activities. The lingering power of therapeutic place and healing memory deepens this affective and performative connection (Conradson, 2005).

\section{Discussion: the therapeutic landscape as performative setting}

Framing a holy well like St. Kieran's (Fig. 4) as a therapeutic assemblage suggests a holistic description of its position within a time-space continuum. One can see a piece of micro-landscape of healing and wellness that bears material objects in a rolling topography (wells, trees, rocks, crosses). One can also see as a second layer on top of that, the complex culturally produced meanings embedded in and shaping those material objects; the identities, especially the health identities, invested in them, and the hue and shade of metaphor on the material. Finally one can see a third layer of people, not ghostly, but solid palimpsestic traces of embodied human occupation and the uses, meanings and constructions that those mobile inhabitations enacted on the site; through their agreements and dissent from given meanings, their performativities (cultural and curative) and embodied positionalities (as participant, believer, patient, cured, observer, cynic), the filling and emptying of the site, and the material and metaphoric footprints on this healing place.

In considering this description in terms of mind/body/spirit health, the freedom to explore such dimensions of healing is never quite so simple. Across history and into the present day, contestations have shaped practice and meaning at the holy well, linked to a range of 'gazes', clerical, colonial and medical (Foucault, 1976; Foley, 2010). Even now, the different constituencies who inhabit the well occasionally clash and tensions exist around 'othered' inhabitations by nominally excluded groups. Travellers in particular, have a deep and unique set of practices at the well, which occasionally brings them into conflict with religious and settled practices. At Tobernalt only travellers walk through the stream in their bare feet or bathe their children as a preventative early-life cure at Father Moore's well.

Holy wells can be described as sites of indigenous health, a concept often discursively understood solely as 'non-white, nonwestern' (Evans, 1957; Wilson, 2003; Kingsley et al., 2009). In the vernacular meanings and performances at the holy well, one can see that they also tapped into a deeply felt health need for an indigenous population with few other medical resources (Wilson, 2003). While that need was often hard to diagnose, it was most certainly felt, and that emotional need was in part met in the affective setting of the well or expressed in notes, pleas and votive offerings left behind. A listing of those elements, structures, appearances and, crucially for the health geographer, cures, has helped to clarify what wells were, how they were materially constructed and what discursive therapeutic powers they held. Those performances combined healing and spiritual dimensions, but as pragmatic health responses in place they were also simple expressions of actions speaking louder than words (Davidson and Smith, 2007).

In returning to Gesler's definition, which balanced out inner meanings and outer contexts, the holy well provides an initial example of a therapeutic assemblage that might be extended to a range of other sites and settings. The individual psyche is engaged with place through a range of affective beliefs, experiences, narratives and embodiments, and as an expressed ownership of self-health. Yet the sites also function as culturally produced settings where wider narratives, customs, meanings and contingent practices are expressed in nominal ownerships of place. It is in the mobile negotiations of these two forms of ownership and inhabitation that the holy well most tellingly speaks and which has wider applicability in other therapeutic settings. This also suggests how other traditional and contemporary therapeutic landscapes might be considered in the future (Bourke, 2001). While Rose and Wylie (2006) see 'landscape as tension', it can equally be examined through a therapeutic lens as an affective place with a charged 
background (Lea, 2009). This deeper engagement with the notion of energies also reflects Lorimer's (2006) invocation of forces and flows that simultaneously acknowledge vernacular and folk knowledges, in this case through indigenous health practices.

In summary, the paper has introduced a new form of traditional therapeutic landscape and illustrated up to a point how a theoretical performative lens can be extended to tangible empirical settings. In proposing an assemblage definition of the well one can also make evident Conradson's (2005) notion of a relational outcome, where therapeutic benefits are negotiable, contingent and framed by affective and performative embodiment in place. The assemblage proposed in Table 1 has a specific health brief and in part reflects the established embedding of relationships between culture, health and place within health geography. Yet in developing the model, the incorporation of recent and exciting theoretical ideas drawn from the broad 'performative turn' and the potential, in particular, to apply notions of inhabitation more fully within the study of health/ medical geographies has been a strong motivating factor. In particular, research that more deeply records and critically studies the places of the senses in a range of therapeutic landscapes seems to me to be a ripe source for future investigation.

\section{References}

Anderson, J., 2010. Understanding Cultural Geography. Routledge, London.

Anderson, K., Smith, S., 2001. Editorial, Emotional geographies. Transactions of the Institute of British Geographers 26, 7-10.

Andrews, G., Kearns, R., 2005. Everyday health histories and the making of place, the case of an English coastal town. Health \& Place 60, 2697-2713.

Backhaus, G., 2009. Phenomenology/Phenomenological Geographies. In: Kitchin, R., Thrift, N. (Eds.), International Encyclopedia of Human Geography, 8. Elsevier pp. 137-144.

Bakhtin, M.M., 1984. Rabelais and His World. Indiana University Press, Bloomington.

Bergholdt, K., 2008. Wellbeing, A Cultural History of Healthy Living. Polity, Cambridge.

Bord, J., Bord, C., 1985. Sacred Waters, Holy Wells and Water Lore in Britain and Ireland. Granada, London.

Bourke, A., 2001. Introduction. In: Rackard, A., O'Callaghan, L. (Eds.), FishStoneWater. Holy Wells of Ireland. Cork, Atrium, pp. 7-12.

Boylan, E., 2002. Tobernalt Holy Well, History and Heritage. St. Johns, Carraroe, Sligo.

Brenneman, W., Brenneman, M., 1995. Crossing the Circle at the Holy Wells of Ireland. University Press of Virginia, Charlottesville.

Broderick, E., 1998. Devotions at holy wells, an aspect of popular religion in the diocese of Waterford and Lismore before the famine. Decies, Journal of the Waterford Archaeological and Historical Society 53, 53-74.

Carroll, M.P., 1999. Irish Pilgrimage, Holy Wells and Popular Catholic Devotion. The Johns Hopkins University Press, Baltimore.

Collins, D., Kearns, R., 2007. Ambiguous Landscapes, Sun, Risk and Recreation on New Zealand Beaches. In: Williams, A. (Ed.), Therapeutic Landscapes. Ashgate, Farnham, pp. 15-32.

Conlon, L., 1999. The holy wells of County Louth. Journal of the County Louth Archaeological and Historical Society 24 (3), 329-345.

Conradson, D., 2005. Landscape, care and the relational self, therapeutic encounters in rural England. Health \& Place 11, 337-348.

Conradson, D., 2007. The Experiential Economy of Stillness, Places of Retreat in Contemporary Britain. In: Williams, A. (Ed.), Therapeutic Landscapes. Ashgate, Farnham, pp. 33-48

Crouch, D., 2000. Places around us, embodied lay geographies in leisure and tourism. Leisure Studies 19, 63-76.

Cummins, S., Curtis, S., Diez-Roux, A., Macintyre, S., 2007. Understanding and representing 'place' in health research, a relational approach. Social Science and Medicine 65, 1825-1838.

Davidson, J., Smith, M., 2007. Emotional Geographies. In: Kitchin, R., Thrift, N. (Eds.) International Encyclopedia of Human Geography, 3. Elsevier, pp. 440-445.

De Certeau, M., 1984. The Practices of Everyday Life. University of California Press, Berkeley.

Deleuze, G., Guattari, F., 1987. A Thousand Plateaus. Capitalism and Schizophrenia The Athlone Press, London.

De Vál, S. (Ed.), Our Lady’s Island, Oileán Mhuire. Insula Beatae Mariae. Dennis Brennan, Our Lady's Island.

Dewsbury, J.D., 2009. Affect. In: Kitchin, R., Thrift, N. (Eds.), International Encyclopedia of Human Geography, 1. Elsevier, pp. 20-24.

Dorn, M., Laws, G., 1994. Social theory, body politics, and medical geography, extending Kearns's invitation. The Professional Geographer 46 (1), 106-110.

Dunkley, C.M., 2009. A therapeutic taskscape, theorizing place-making, discipline and care at a camp for troubled youth. Health \& Place 15, 88-96.
Dyck, I., Kontos, P., Angus, J., McKeever, P., 2005. The home as a site for long-term care, meanings and management of bodies and spaces. Health \& Place 11, 173-185.

Eliade, M., 1961. Images and Symbols, Studies in Religious Symbolism. Sheed, Andrews and McMeel, Mission.

Evans, E.E., 1957. Irish Folk Ways. Routledge \& Kegan Paul, London.

Eyles, J., Williams, A. (Eds.), 2008. Ashgate, Farnham.

Foley, R., 2010. Healing Waters, Therapeutic Landscapes in Historic and Contemporary Ireland. Ashgate, Farnham.

Foucault, M., 1976. The Birth of the Clinic, An Archaeology of Medical Perception. Tavistock, London [1963].

Gerten, D., 2008. Water of life, water of death, Pagan notions of water from antiquity. In: Shaw, S., Francis, A. (Eds.), Deep Blue, Critical Reflections on Nature, Religion and Water. Equinox, London, pp. 33-48

Gesler, W.M., 1992. Therapeutic landscapes, medical Issues in the light of the new cultural geography. Social Science and Medicine 34 (7), 735-746.

Gesler, W.M., 1993. Therapeutic landscapes, theory and a case study of Epidauros, Greece. Environment and Planning D 11 (2), 171-189.

Gesler, W.M., 1996. Lourdes, healing in a place of Pilgrimage. Health \& Place 2 (2), 95-105.

Gesler, W.M., 1998. Bath's reputation as a healing place. In: Kearns, R., Gesler, W. (Eds.), Putting Health into Place, Landscape, Identity and Well-Being.. Syracuse University Press, Syracuse, pp. 17-35.

Gesler, W.M., 2003. Healing Places. Rowman \& Littlefield, Lanham.

Gesler, W.M., Kearns, R., 2002. Culture/Place/Health. Routledge, London.

Graber, L.H., 1976. Wilderness as Sacred Space. Association of American Geographers, Washington.

Hall, S.C., Hall, S.C., 1843. Ireland, its scenery and character. How \& Parsons, London.

Harbison, P., 1991. Pilgrimage in Ireland, The Monuments and the People. Barrie and Jenkins, London.

Hardy, P.D., 1836. The Holy Wells of Ireland. Hardy and Walker, Dublin.

Healy, E., 2001. Search of Ireland's Holy Wells. Wolfhound Press, Dublin.

Ingold, T., 2000. The Perception of the Environment, Essays in Livelihood, Dwelling and Skill. Routledge, London.

Jackson, P., 1989. Maps of Meaning, An Introduction to Cultural Geography. Unwin Hyman, London.

Jones, O., Cloke, P., 2002. Tree Cultures, The Place of Trees and Trees in their Place. Berg, Oxford.

Kearns, R., 2005. Medical geography, making space for difference. Progress in Human Geography 19 (2), 251-259.

Kearns, R., Gesler, W.M. (Eds.), 1998. Syracuse University Press, Syracuse.

Kearns, R., Moon, G., 2002. From medical to health geography, novelty, place and theory after a decade of change. Progress in Human Geography 26 (5), 605-625.

Kingsley, J.Y., Townsend, M., Phillips, R., Aldous, D., 2009. "If the land is healthy ... it makes the people healthy", The relationship between caring for Country and health for the YortaYorta Nation, Boonwurrung and Bangerang Tribes. Health \& Place 15, 291-299.

Knott, K., Franks, M., 2007. Secular values and the location of religion, a spatial analysis of an English medical centre. Health \& Place 13, 224-237.

Lea, J., 2006. Experiencing festival bodies: connecting massage and wellness. Tourism Recreation Research 31 (1), 57-66.

Lea, J., 2008. Retreating to nature, rethinking 'therapeutic landscapes'. Area 40 (1), 90-98.

Lea, J., 2009. Post-Phenomenology/Post-Phenomenological Geographies. In: Kitchin, R., Thrift, N. (Eds.), International Encyclopedia of Human Geography, 8. Elsevier, pp. 373-378.

Logan, P., 1980. The Holy Wells of Ireland. Colin Smythe, Gerrards Cross.

Lorimer, H., 2005. Cultural geography, the busyness of being 'more-than-representational'. Progress in Human Geography 29 (1), 83-94.

Lorimer, H., 2006. Herding memories of humans and animals. Environment and Planning D 24, 497-518.

Lorimer, H., 2008. Cultural geography, non-representational conditions and concerns. Progress in Human Geography 32 (4), 551-559.

Lorimer, J., 2009. Posthumanism/Posthumanistic Geographies. In: Kitchin, R., Thrift, N. (Eds.), International Encyclopedia of Human Geography, 8. Elsevier, pp. 344-354.

McCormack, D., 2004. An event of geographical ethics in spaces of affect. Transactions of the Institute of British Geographers 28, 488-507.

MacNeill, M., 1982. The Festival at Lughnasa. UCD Folklore Department, Dublin.

Merleau-Ponty, M., 1962. Phenomenology of Perception. Routledge and Kegan Paul, London [1942].

Milligan, C., Bingley, A., 2007. Restorative places or scary spaces? The impact of woodland on the mental well-being of young adults. Health \& Place 13, 799811.

Nash, C., 2000. Performativity in practice: some recent work in cultural geography. Progress in Human Geography 24 (4), 653-664.

National Folklore Collection, 1934. Manuscript 468, Cúntaisí ar Thoibreacha Beannuithe do fuairtear ó Mhúinteorí ar fuaid Chúige Laighean. National Folklore Collection, Dublin.

Ó'Cadhla, S., 2002. The Holy Well Tradition. The Pattern of St Declan, Ardmore, County Waterford, 1800-2000. Four Courts Press, Maynooth.

O'Connell, P., 1957. Castle Kieran. Ríocht na Midhe 1 (3), 17-33.

Paterson, M., 2005. Affecting Touch, Towards a 'Felt' Phenomenology of Human Touch'. In: Davidson, J., Bondi, L., Smith, M. (Eds.), Emotional Geographies. Ashgate, Farnham, pp. 161-173. 
Rattue, J., 1995. The Living Stream, Holy Wells in Historical Context. The Boydell Press, Woodbridge.

Rickard, A., O’Callaghan, L., 2001. FishStoneWater. Holy Wells of Ireland. Atrium, Cork.

Rose, M., Wylie, J., 2006. Animating landscape. Environment and Planning D 24, 475-479.

Shackley, M., 2001. Managing Sacred Sites.. Continuum, London.

Shaw, S., Francis, A. (Eds.), 2008. Equinox.

Strang, V., 2004. The Meaning of Water. Berg Oxford.

Taylor, L., 1995. Occasions of Faith, An Anthropology of Irish Catholics. University of Pennsylvania Press, Philadelphia.

Thrift, N., 2008. Non-representational Theory, Space |Politics $\mid$ Affect. Routledge, London.

Tuan, Y.-F., 1974. Topophilia, A Study of Environmental Perception, Attitudes and Values. Columbia University Press, New York.
Turner, V., 1973. The center out there. Pilgrim's Goal. The History of Religions 12 (3) 191-230.

Turner, V., Turner, E., 1978. Image and pilgrimage in christian culture, Anthropological Perspectives. Columbia University Press, New York.

Varner, G.R., 2002. Sacred Wells. A Study in the History, Meaning and Mythology of Holy Wells and Waters. Publish America, Baltimore.

Williams, A., 1999a. Introduction. In: Williams, A. (Ed.), Therapeutic Landscapes, The Dynamic between Place and Wellness. University Press of America, Lanham, pp. 1-11.

Williams, A. (Ed.), University Press of America, Lanham.

Williams, A. (Ed.), 2007. Therapeutic Landscapes. Ashgate, Farnham.

Wilson, K., 2003. Therapeutic landscapes and first nations peoples, an exploration of culture, health and place. Health \& Place 9 (1), 83-93.

Wylie, J., 2007. Landscape. Routledge, Abingdon. 